\title{
APPLICATION OF ELECTROCHEMICAL REDOX CYCLING: TOWARD DIFFERENTIATION OF DOPAMINE AND NOREPINEPHRINE
}

Mengjia $\mathrm{Hu}$, Department of Chemistry and Biochemistry, University of Arkansas, Fayetteville, AR 72701, mhu@uark.edu, 479-575-3343

Ingrid Fritsch*, Department of Chemistry and Biochemistry, University of Arkansas, Fayetteville, AR 72701, ifritsch@uark.edu, 479-575-6499

*To whom correspondence should be addressed. 


\section{SUPPORTING INFORMATION}

Supporting information includes description of device, electrochemical setup, and chemicals used, as well as summaries and ANOVA tests of processed data of generators alone, generators and collectors with redox cycling signals for $50 \mu \mathrm{M}$ DA, NE and DA-NE mixture of $50 \mu \mathrm{M}$ of each from three sets of experiments. 


\section{DEVICE, ELECTROCHEMICAL SETUP, AND CHEMICALS USED}

Microfabricated 1 in. $\times 1$ in. model chips containing 18 individually-addressable gold microband electrodes that are $2.00 \mathrm{~mm}$ long, $4.0 \mu \mathrm{m}$ wide and separated by $4.0 \mu \mathrm{m}$ gaps were used here. Microfabrication details are described elsewhere. ${ }^{1,2}$ A bipotentiostat equipped with a Faraday cage and a picoamp booster (CHI 760B, CH Instruments, Austin, TX) was used to perform the electrochemical experiments. $\mathrm{A} \mathrm{Ag} / \mathrm{AgCl}$ (saturated $\mathrm{KCl}$ ) reference electrode and $\mathrm{Pt}$ wire auxiliary electrode were employed. As shown in Figure 2 of the main document, two shorted generator microbands and three shorted collector microbands, in an alternating arrangement, served as the first and second sets of working electrodes, respectively. They were activated to have a specified gap width $(4,12,20$ and $28 \mu \mathrm{m}$, edge to edge distance between the neighboring generator and collector electrodes).

All chemicals were used as received unless otherwise stated. Water (ACS reagent grade, $18 \mathrm{M} \Omega \mathrm{cm}$ or greater) was obtained from Ricca Chemical (Arlington, TX, USA). Before and after redox cycling studies involving catecholamines, all working electrodes were characterized by cyclic voltammetry (CV) using a solution of $1.0 \mathrm{mM}$ potassium ferricyanide (EM Science, Gibbstown, NJ, USA) in $100.0 \mathrm{mM} \mathrm{KCl} \mathrm{(BDH,} \mathrm{Radnor,} \mathrm{PA,} \mathrm{USA).} \mathrm{The} \mathrm{supporting} \mathrm{electrolyte}$ consisted of artificial cerebral spinal fluid (aCSF) buffer (100 mM NaCl (EMD, Gibbstown, NJ, USA), $5.0 \mathrm{mM} \mathrm{KCl}, 1.2 \mathrm{mM} \mathrm{NaH}{ }_{2} \mathrm{PO}_{4}$ (Alfa Aesar, Ward Hill, MA, USA), $5.0 \mathrm{mM} \mathrm{NaHCO}$ (J.T.Baker, Phillipsburg, NJ, USA), 10 mM glucose (BDH), 2.5 mM HEPES (Alfa Aesar), 1.2 $\mathrm{mM} \mathrm{MgSO}_{4}, 1.0 \mathrm{mM} \mathrm{CaCl}_{2}$ (Alfa Aesar)) at $7.4 \mathrm{pH}$. (-)-Norepinephrine, $\geq 98 \%$, crystalline was obtained from Sigma, St. Louis, MO, USA and dopamine hydrochloride, 98.5\% from Alfa Aesar. 


\section{ELECTROCHEMICAL RESPONSES AT GENERATOR ELECTRODES WITHOUT}

\section{AND WITH REDOX CYCLING}

The percentage differences between the sum of the generator signals (current value measured at the plateau of the sigmoidal cyclic voltammetric response, not normalized) for the individual components $\left(i_{G, D A}\right.$ and $i_{G, N E}$, for $50 \mu \mathrm{M}$ DA and $50 \mu \mathrm{M} \mathrm{NE}$ in separate solutions) and the generator signal for the mixture $\left(i_{G, \text { Mixture }}\right.$ for $50 \mu \mathrm{M}$ DA $+50 \mu \mathrm{m}$ NE combined in a single solution) were calculated for each gap condition using eq. S-1,

$$
\text { Percentage difference }=\frac{\left(i_{G, D A}+i_{G, N E}\right)-i_{G, \text { Mixture }}}{i_{G, \text { Mixture }}} \times 100 \%
$$

Results for the generator current without redox cycling and with redox cycling of three sets of experiments involving different gaps, and each set performed using a different electrode chip from a different silicon wafer, are listed in Table S-1 and Table S-2, respectively.

Table S-1. Percentage difference between the sum of the generator currents without redox cycling for the individual components and the mixture, following eq. S-1, taken from three different sets of experiments (\#1, \#2, and \#3), each involving the series of gaps (and therefore different electrodes within the same chip), where each set was performed with a different electrode chip taken from a different silicon wafer.

\begin{tabular}{|l|l|l|l|l|l|}
\hline \multicolumn{1}{|c|}{ Gap $(\mu \mathrm{m})^{*}$} & 4 & 12 & 20 & 28 & Average \\
\cline { 3 - 7 } & & & & & \\
\hline$\# 1$ & $10.83 \%$ & $-63.67 \%$ & $9.10 \%$ & $33.52 \%$ & $-2.56 \%$ \\
\hline$\# 2$ & $2.24 \%$ & $-28.71 \%$ & $2.14 \%$ & $2.11 \%$ & $-5.56 \%$ \\
\hline$\# 3$ & $-8.00 \%$ & $2.63 \%$ & $2.47 \%$ & $21.68 \%$ & $4.70 \%$ \\
\hline Average & $1.69 \%$ & $-29.92 \%$ & $4.57 \%$ & $19.11 \%$ & $-1.14 \%$ \\
\hline
\end{tabular}


* "Gap" refers to the edge-to-edge separation between generator and collector electrodes. The data in this table were obtained without redox cycling, and thus, the "collector" electrodes were not activated.

The ANOVA test at the $95 \%$ confidence level $\left(\mathrm{F}_{\text {column }}=3.514<\mathrm{F}_{\text {table }}=4.066\right.$ and $\mathrm{F}_{\text {row }}=$ $0.153<\mathrm{F}_{\text {table }}=4.256$ ) indicates that there is no statistically significant difference among replicates and different gap conditions for generator current without redox cycling.

Table S-2. Percentage difference between the sum of the generator currents with redox cycling for the individual components and mixture, following eq. S-1, for the same electrodes and chips as in Table S-1, except that the collector electrodes were activated.

\begin{tabular}{|l|l|l|l|l|l|}
\hline \multicolumn{1}{|c|}{ Gap $(\mu \mathrm{m})$} & 4 & 12 & 20 & 28 & Average \\
\hline$\# 1$ & & & & & \\
\hline$\# 2$ & $9.31 \%$ & $-0.96 \%$ & $3.07 \%$ & $25.74 \%$ & $9.29 \%$ \\
\hline$\# 3$ & $-1.86 \%$ & $-26.47 \%$ & $5.28 \%$ & $-2.94 \%$ & $-6.50 \%$ \\
\hline Average & $-1.78 \%$ & $0.51 \%$ & $-1.40 \%$ & $20.05 \%$ & $4.34 \%$ \\
\hline
\end{tabular}

* "Gap" refers to the edge-to-edge separation between generator and collector electrodes.

The ANOVA test at the $95 \%$ confidence level $\left(\mathrm{F}_{\text {column }}=2.109<\mathrm{F}_{\text {table }}=4.066\right.$ and $\mathrm{F}_{\text {row }}=$ $1.781<\mathrm{F}_{\text {table }}=4.256$ ) indicates that there is no statistically significant difference among replicates and different gap conditions for the generator current with redox cycling.

These results suggest that the generator signal is not affected by the following chemistry interactions between DA and NE. Thus, the current at the generators can provide information of the total concentration of the catecholamines. 


\section{ELECTROCHEMICAL RESPONSES AT COLLECTOR ELECTRODES WITH REDOX}

\section{CYCLING}

The percentage differences between the collector signal for the DA alone ( $i_{C, D A}$, for $\left.50 \mu \mathrm{M} \mathrm{DA}\right)$ and that for the DA-NE mixture $\left(i_{C, \text { Mixture }}\right.$, for $\left.50 \mu \mathrm{M} \mathrm{DA}+50 \mu \mathrm{M} \mathrm{NE}\right)$ were calculated for each gap condition using eq. S-2 and are listed in Table S-3. The raw collector data used to produce Table S-3 were obtained simultaneously during the same redox cycling experiments as the raw generator data used to produce Table S-2.

$$
\text { Percentage difference }=\frac{i_{C, D A}-i_{C, \text { Mixture }}}{i_{C, \text { Mixture }}} \times 100 \%
$$

Table S-3 Percentage difference between the collector currents (redox cycling) for the individual component DA and the DA-NE mixture, for the same experiments as in Table S-2.

\begin{tabular}{|l|l|l|l|l|l|}
\hline \multicolumn{1}{|r|}{ Gap $(\mu \mathrm{m})$} & 4 & 12 & 20 & 28 & Average \\
\hline$\# 1$ & $-6.94 \%$ & $-19.26 \%$ & $7.20 \%$ & $11.42 \%$ & $-1.89 \%$ \\
\hline$\# 2$ & $-40.00 \%$ & $-21.60 \%$ & $-0.12 \%$ & $-0.57 \%$ & $-15.57 \%$ \\
\hline$\# 3$ & $-60.03 \%$ & $-21.77 \%$ & $10.03 \%$ & $38.38 \%$ & $-8.35 \%$ \\
\hline Average & $-35.66 \%$ & $-20.88 \%$ & $5.71 \%$ & $16.41 \%$ & $-8.60 \%$ \\
\hline
\end{tabular}

* "Gap" refers to the edge-to-edge separation between generator and collector electrodes.

The ANOVA test at the $95 \%$ confidence level $\left(\mathrm{F}_{\text {column }}=5.978>\mathrm{F}_{\text {table }}=4.066\right.$ and $\mathrm{F}_{\text {row }}=$ $0.239<\mathrm{F}_{\text {table }}=4.256$ ) indicates that there is no statistically significant difference between replicates of the collector current for a fixed gap condition. However, there $\underline{i s}$ a significant 
difference among different gap conditions_—with increasing gap width, the collector current of the DA-NE mixture approaches and then drops below that for the DA alone.

\section{REFERENCES}

(1) Aggarwal, A. Studies Toward the Development of a Microelectrode Array for Detection of Dopamine through Redox Cycling. Ph.D. Dissertation, University of Arkansas, Fayetteville, AR, 2011.

(2) Aggarwal, A. H., M.; Fritsch, I. Anal. Bioanal. Chem. 2013, 405, 3859-3869. 